\title{
Electron collection radius of an electrostatic probe immersed in a low-pressure plasma $\left({ }^{*}\right)$
}

\author{
M. Bacal, A. M. Bruneteau and M. Nachman (**) \\ Laboratoire de Physique des Milieux Ionisés, Ecole Polytechnique, 91128 Palaiseau Cedex, France
}

(Reçule 19 août 1980, révisé le 29 octobre, accepté le 7 novembre 1980)

\begin{abstract}
Résumé. - On décrit une technique pour déterminer la zone d'attraction d'une sonde électrostatique. Un faisceau laser pulsé, coaxial avec la sonde crée, par photodétachement des ions négatifs, une bouffée d'électrons. La mesure sur la sonde de l'amplitude de cette impulsion d'électrons en fonction du diamètre du faisceau laser montre que la distance d'attraction des électrons par la sonde est le double de l'épaisseur de la gaine donnée par Kiel.
\end{abstract}

Abstract. - A technique is described for determining the electron collection distance by an electrostatic probe. A pulsed laser beam coaxial with the probe creates, by the photodetachment of plasma negative ions, a burst of electrons. The measurement of the amplitude of the probe electron current pulse as a function of the laser beam diameter indicates that the electron collection distance by the probe is twice the sheath thickness given by Kiel.

1. Introduction. - The Langmuir probe is extensively used to measure electron densities and temperatures in plasmas [1]. For a correct interpretation of the experimental results, the thickness of the region from where the charged particles are collected by a probe has to be known. This is the case in the diagnosis of negative ions in plasmas by the photodetachment technique. Many authors have been interested by the calculation of the sheath thickness. However a significant electric field can exist beyond the sheath [2] so that carriers from a much larger region can be drawn to an attracting probe.

In the present work we would like to report on a technique, which makes it possible to determine the thickness of the region from where charged particles are collected by a probe. The experiments were carried out with a cylindrical electron-attracting probe, immersed in a hydrogen plasma.

2. Experimental technique. - A positively biased cylindrical probe is immersed in a plasma containing electrons and positive and negative ions. A cylindrical region around the probe is irradiated by a pulsed laser beam coaxial with the probe. The short laser pulse creates a burst of electrons, by photodetaching them from the negative ions [3]. These electrons,

(*) La version française de cet article a été soumise pour publication aux Comptes Rendus de l'Académie des Sciences.

(**) Ecole Polytechnique, Montréal, Canada. attracted by the probe, give rise to a short pulse of current in the probe circuit. By measuring the amplitude of the current pulse as a function of laser beam diameter, the collection radius, that is the radius of the cylindrical region from where electrons are drawn to the probe, can be obtained.

For the present experiments the set-up described in reference [3] was used. The plasma was produced in a 151 glass vessel (Fig. 1), containing hydrogen at low-pressure (around $10^{-2}$ torr). Electrons emitted from a negatively biased filament, and subsequently accelerated by a grounded grid acting as an anode, ionize the gas and thus a plasma, containing electrons and positive and negative hydrogen ions, is obtained.

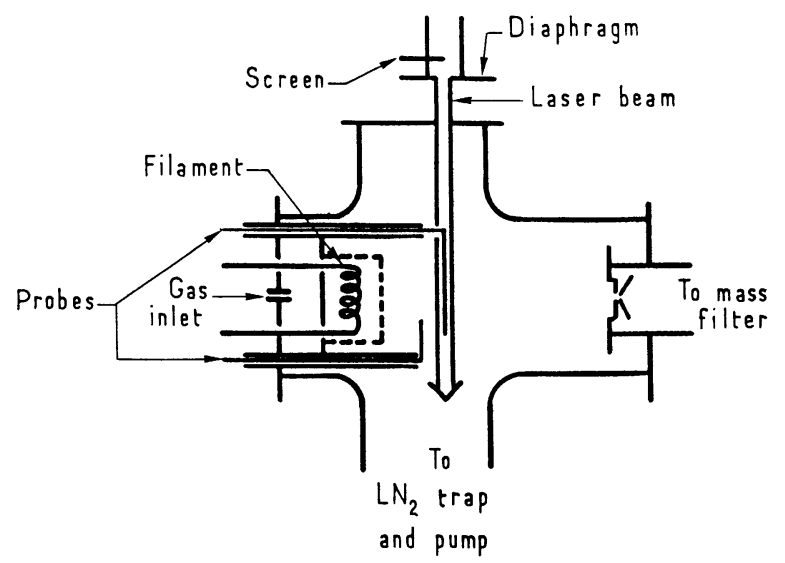

Fig. 1. - Experimental set-up. 
A thin probe (a tungsten wire $6.1 \mathrm{~cm}$ long and $5 \times 10^{-3} \mathrm{~cm}$ in diameter) served for measuring the plasma density $\left(n_{+}\right)$and the electron temperature $\left(k T_{\mathrm{e}}\right)$. A thicker, self-supporting probe (a tungsten wire $10 \mathrm{~cm}$ long and $5 \times 10^{-2} \mathrm{~cm}$ in diameter) served for measuring the collection radius. A pulsed cylindrical ruby laser beam, coaxial with the thick tungsten probe, served to create a sudden increase in the electron population around the probe, by photodetachment. This resulted in a pulse, $\Delta i^{-}$, in the electron current to the positively biased probe. The variation of $\Delta i^{-} v s$. laser beam diameter $\left(D_{\mathrm{L}}\right)$ has been measured for several plasma densities in the range from $1 \times 10^{9}$ to $1.4 \times 10^{10} \mathrm{~cm}^{-3}$ and for a probe potential of +5 or $+40 \mathrm{~V}$. The collection diameter $\left(D_{\mathrm{e}}\right)$ is the $D_{\mathrm{L}}$ value for which the variation of $\Delta i^{-} v s$. $D_{\mathrm{L}}$ comes to a plateau. The beam cross-section was varied by means of diaphragms of different diameters (between 2 and $9 \mathrm{~mm}$ ). The holes defined by the diaphragms were centred around the probe. A small screen (a wire $1.5 \mathrm{~mm}$ in diameter) was inserted between the laser and the probe in order to eliminate the spurious signals due to the irradiation of the probe by the laser light.

3. Results and discussion. - In figure $2, \Delta i^{-}$is plotted as a function of $D_{L}$ for several plasma densities. The probe potential was $40 \mathrm{~V}\left({ }^{1}\right)$ and the pressure $1.4 \times 10^{-2}$ torr.

In figure $3, \Delta i^{-}$is represented as a function of $D_{\mathrm{L}}$ for two different probe potentials $(5 \mathrm{~V}$ and $40 \mathrm{~V})$; the plasma density was $2.7 \times 10^{9} \mathrm{~cm}^{-3}$ and the gas pressure, $1.4 \times 10^{-2}$ torr. It is seen that the collection diameter for $V_{\mathrm{p}}=40 \mathrm{~V}$ is about twice that for $V_{\mathrm{p}}=5 \mathrm{~V}(8 \mathrm{vs} .4 \mathrm{~mm})$.

In table I the experimentally obtained thickness of the collection region $\left(d_{\mathrm{c}}\right)$ is compared with the theoretically derived values for the sheath thickness $(d)$. We have :

$$
d_{\mathrm{c}}=\frac{1}{2}\left(D_{\mathrm{e}}-D_{\mathrm{p}}\right) \text {, }
$$

where $D_{\mathrm{p}}$ is the probe diameter. On the other hand, $d_{\mathrm{s}}$ can be calculated using the analytical relationship

( $\left.{ }^{1}\right)$ The plasma potential, derived from the thin probe characteristics, was found to be less than $1.0 \mathrm{~V}$. This means that the probeplasma potential was, practically, equal to the potential applied to the probe from the external source.

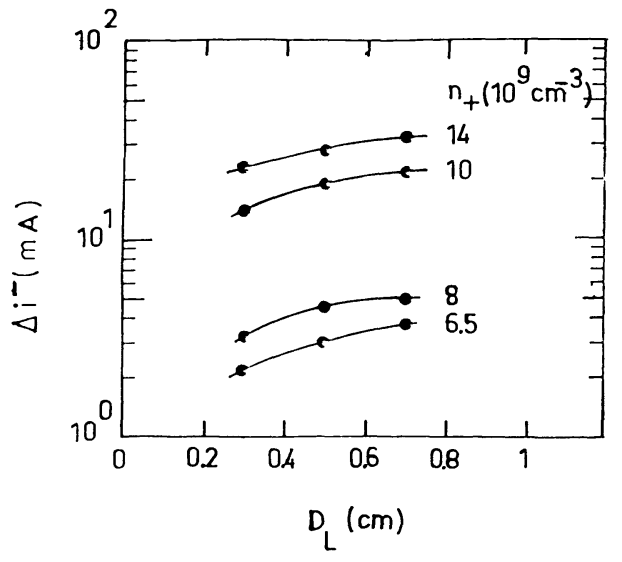

Fig. 2. - Dependence of $\Delta i^{-}$on laser beam diameter at different plasma densities, for $V_{\mathrm{p}}=+40 \mathrm{~V}$ and at a gas pressure of $1.4 \times 10^{-2}$ torr

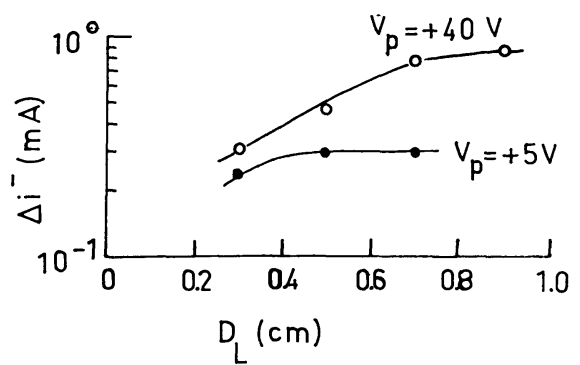

Fig. 3. - Dependence of $\Delta i^{-}$on laser beam diameter for two different probe potentials $(+5 \mathrm{~V}$ and $+40 \mathrm{~V}$ ), at a plasma density of $2.7 \times 10^{9} \mathrm{~cm}^{-3}$ and a gas pressure of $1.4 \times 10^{-2}$ torr.

for the sheath thickness given by Kiel [4]. Kiel assumes that the potential field near a probe consists of two distinct regions : in the sheath the potential decays very rapidly and charge separation occurs. The sheath boundary is defined by the condition of quasi-neutrality. Beyond the sheath, there is a slow variation of the potential. The presence of this weak electric field beyond the sheath is a possible reason for $d_{\mathrm{c}}$ to be larger than $d_{\mathrm{s}}$.

Kiel also assumes that the plasma electrons exhibit a maxwellian distribution. In our plasma the electron energy distribution is not always maxwellian; when non-maxwellian, it can be approximated by two maxwellian distributions, characterized each by a certain temperature. The lowest temperature is considered in calculating $d_{s}$, since most of the plasma electron population is characterized by this tempe-

Table I. - Comparison between the measured thickness of the collection region $d_{\mathrm{c}}$ and the sheath thickness $d_{\mathrm{s}}$.

\begin{tabular}{|c|c|c|c|c|c|c|}
\hline \multirow[b]{2}{*}{$\begin{array}{c}n_{+} \\
10^{9} \mathrm{~cm}^{-3}\end{array}$} & \multirow[b]{2}{*}{$\begin{array}{c}k T_{\mathrm{e}} \\
10^{-2} \mathrm{eV}\end{array}$} & \multirow[b]{2}{*}{$\underset{10^{-3}}{\lambda_{\mathrm{D}}} \mathrm{cm}$} & \multicolumn{2}{|c|}{$V_{\mathrm{p}}=5 \mathrm{~V}$} & \multicolumn{2}{|c|}{$V_{\mathrm{p}}=40 \mathrm{~V}$} \\
\hline & & & $\begin{array}{c}d_{\mathrm{s}} \\
10^{-1} \mathrm{~cm}\end{array}$ & $\begin{array}{c}d_{\mathrm{c}} \\
10^{-1} \mathrm{~cm}\end{array}$ & $\begin{array}{c}d_{\mathrm{s}} \\
10^{-1} \mathrm{~cm}\end{array}$ & $\begin{array}{c}d_{\mathrm{c}} \\
10^{-1} \mathrm{~cm}\end{array}$ \\
\hline- & - & - & - & - & - & - \\
\hline 1.4 & 29 & 11 & 0.82 & & 2.3 & $>3.8$ \\
\hline 2.7 & 41 & 9 & 0.6 & 1.8 & 1.7 & 3.8 \\
\hline 7.6 & 76 & 7 & 0.37 & & 1 & 2.3 \\
\hline
\end{tabular}


rature. For the ion temperature a value of $300 \mathrm{~K}$ is assumed.

From the data of table I it may be inferred that, for the type of plasma used in the present experiments, the region from where electrons are drawn to the probe extends beyond the sheath, the thickness of this region being almost twice as large as the sheath thickness and a few tens of times as large as the Debye distance $\left(\lambda_{\mathrm{D}}\right)$, for a probe potential of $40 \mathrm{~V}$. We interpret the fact that the measured electron collection radius is larger than the calculated radius of the sheath boundary by the existence of a weak electric field beyond this boundary.

The knowledge of $d_{\mathrm{c}}$ is important for plasma diagnostics. When using electron collecting probes, it should be verified that the plasma is homogeneous on a scale comparable to $d_{\mathrm{c}}$. When lasers are used in connection with probes, as in the measurement of negative ion density by photodetachment, the diameter of the laser beam has to be larger than $d_{\mathrm{c}}$.

\section{References}

[1] SwIFT, J. D. and Schwar, M. J. R., Electrical Probes for Plasma Diagnostics (London Iliffe Books, New York American Elsevier) 1969.

[2] Laframboise, J. G., Theory of spherical and cylindrical Langmuir probes in a collisionless, maxwellian plasma at rest.
University of Toronto, Institute for Aerospace Studies, Report No 100 (1966).

[3] Bacal, M., Hamilton, G. W., Bruneteau, A. M., Doucet, H. J. and TAILlET, J., Rev. Sci. Instrum. 50 (1979) 719.

[4] KIEL, R. E., AIAA J. 6 (1968) 708. 